\title{
CLINICO-RADIOLOGICAL EVALUATION OF LEGG- CALVE-PERTHES DISEASE MANAGED BY PROXIMAL FEMORAL VARUS DEROTATION OSTEOTOMY: A RETROSPECTIVE STUDY
}

\author{
Amitosh Mishra*, Ajai Singh ${ }^{\circledR}$, Sibananda Ratha\#, Syed Faisal Afaque \\ \& Anil Kumar Panda^
}

*MB,BS, D.Orth, DNB(Orth), MNAMS, Fellowship in Paediatric Orthopaedic Surgery, Assistant Professor Orthopaedics, Integral Institute of Medical Sciences \& Research, Integral University, Lucknow. ${ }^{\circledR}$ Professor \& HOD, Paediatric Orthopaedic Surgrey, King George's Medical University, Lucknow. \#Senior Resident Orthopaedics, King George’s Medical University. ${ }^{\$}$ Senior Resident Orthopaedics, King George's Medical University. 'Senior Resident Paediatric Orthopaedics, King George's Medical University, Lucknow, India.

\begin{abstract}
Legg-Calve-Perthes disease is a juvenile idiopathic aseptic and non-inflammatory osteonecrosis of immature hip. It is associated with both substantial hip pain and dysfunction during the disease process as well as later in adulthood. The goals of treatment are to decrease pain, reduce the loss of hip motion, and prevent or minimize permanent femoral head deformity.

Children with Perthes disease, of both genders were managed by proximal femoral varus derotation osteotomy. Evaluation was done in terms of; clinical symptoms and signs, Harris hip score, and radiologically with X-rays.

The results indicated improvement in pain, limp, abduction, internal rotation and Harris Hip Score which was statistically significant.

In conclusion, proximal femoral varus derotation osteotomy is an acceptable method for management of patients with Legg-Calve-Perthes disease. This surgery led to decrease in pain, limping, and an increase in range of motion.

Key words: legg-calve-perthes, proximal femoral varus derotation osteotomy, surgical femoral head containment
\end{abstract}

\section{Introduction}

T egg-Calve-Perthes disease (LCPD) is a juvenile idiopathic aseptic, noninflammatory, immature hip osteonecrosis in which femoral epiphysis blood supply is not adequate and the bone dies temporarily, followed by subchondral fracturing, fragmentation, revascularization and remodeling. Both severe hip pain and dysfunction during the disease phase and later in adulthood are associated with it. Vascular occlusion is reversible, with complete epiphysis revascularization occurring over a span of 2-4 years if the child is under 12 years of age at the onset of the disease. LeggCalve-Perthes disease predominantly occurs in boys between the ages of 4 and 8 and has been associated with socioeconomic disadvantage in a number of small hospital-based studies ${ }^{1-3}$. If treatment is not initiated early in the disease process, eventual flattening and subluxation of the hip joint occurs. It is a major precipitant of premature osteoarthritis of the hip and frequently necessitates hip replacement in early adulthood $^{4,5}$. It is one of the most common, but most poorly understood disorders encountered by pediatric orthopedic surgeons. Incidence rates vary considerably between countries though there is also significant variation within 
countries and even within regions. Many children, especially those until age 6 , the initiation of the disease is clearly asked to refrain from contact sports or games that affect the hip. The best care choice remains unknown for older children (onset of Perthes after age 6). Prolonged periods of non-weight bearing, osteotomy (femoral or pelvic) and the form of hip distraction using an external fixator are current treatment options for older children above 8 years of age.

The aims of therapy are to alleviate discomfort, to decrease hip mobility loss and to prevent or minimize permanent femoral head deformity, so that the risk of developing adult extreme degenerative arthritis can be minimized. To assess risks and treatment options, assessment by a pediatric orthopedic surgeon is recommended. Younger kids get a better prognosis than older kids. Surgical containment has become widely accepted as the best method for treating LeggCalve-Perthes disease ${ }^{6}$. Containment treatment is designed to center the femoral head within the acetabulum during the period of "biologic plasticity". This helps the acetabulum during the healing process to act as a mold ${ }^{7}$. Either proximal femoral varus derotation osteotomy or Salter innominate osteotomy have been the most popular methods for surgical containment ${ }^{8,9}$. Any of these methods can provide sufficient control for mild to moderate LCPD, but in more extreme cases, they may be problematic. About 70-90 percent satisfactory results were reported by advocates of proximal femoral varus derotation osteotomy ${ }^{10-13}$.

The aim of this study is to analyze the clinico-radiological evaluation of LeggCalve-Perthes disease managed by Proximal Femoral Varus Derotation Osteotomy.

\section{Patients \& methods}

This open ended cohort study was conducted over a period of one year, on patients diagnosed clinically and radiologically as Perthes disease and operated upon between 2012 to 2017, presenting at the outdoor department of Pediatric Orthopedic Surgery, King George's Medical University, Lucknow, India.

All the children (up to 16 years) presenting with Perthes disease, of either sex and willing to get enrolled in the study and were managed by proximal femoral varus derotation osteotomy were included in the study. We excluded the patients if they had any other cause of avascular necrosis of femoral head, like post traumatic, post infective; patient presenting with blood dyscrasias like hemophilia, sickle cell disease; patient on steroids, subjects with associated neuromuscular disorder, associated congenital deformity of lower limb, and patients with metabolic diseases such as Rickets.

The assessment tools used in this study were; history, clinical examination for pain, Trendelenburg gait, range of motion and shortening, Harris hip score, X-ray, MRI and statistical analysis of the data collected.

Patient was placed in supine on the operating table and lateral approach taken for exposure. The level of the osteotomy marked at the level of the lesser trochanter or slightly distal with image intensifier. Subtrochanteric osteotomy is done by oscillating saw and the fragments are fixed with a pre-bent plate $(3.5 \mathrm{~mm}$ Dynamic Compression Plate) to ensure a varus angulation of 20 degree done at an aim to achieve the neck shaft angle of 110-115 degree to confirm the femoral head centered concentrically in the acetabulum. Epiphyseodesis of the greater trochanter is done to prevent relative trochanter overgrowth by inserting one screw through the greater trochanter. Irrigate the wound and close in layers, insert a suction drain if needed. Stitches are removed on 12th postoperative day. Follow-up is done at 4 
weeks interval till 3 months. Non weight bearing for 8-10 weeks until union occurs. After 3 months, follow-up done at 12 weeks interval with relevant shoe raise, in patients complaining of limping. Implant removal done after 2 years.

\section{Results}

In the current study a total of 19 patients were included out of which 14 (73.68\%) were males and $5(26.32 \%)$ were females. The mean duration of follow-up was $51.67 \pm 6.95$ months. Amongst the study population, $73.68 \%$ (14/19) patients underwent surgery at age between 6-10 years. None of the patients had surgery at less than 6 years and $26.32 \%(5 / 19)$ had surgery at the age more than 10 years. There was almost an equal incidence of laterality, with right sided involvement being seen in $47.37 \%$ (9/19) patients and left sided involvement being seen in 47.37 (9/19) patients. Only 5.26\% case (1/19) had a bilateral involvement. Limping was a universal finding in all cases. The classical symptom of painless limp was seen in $63.16 \%(12 / 19)$ cases whereas $36.84 \% \quad(7 / 19)$ patients complained from painful limping.
Pain (measured by VAS) was found in $36.84 \%(7 / 19)$ cases, which was reduced to $5.26 \%(1 / 19)$ cases at the final followup. This change in proportion of pain was significant $(\mathrm{p}=0.017)$. The Trendelenburg gait was present in $94.7 \%$ (18/19) patients which was reduced to $47.4 \%$ (9/19) patients at final follow-up which was found to be highly significant ( $\mathrm{p}=0.001$ ).

On comparing the pre-operative and final follow-up range of abduction in the patients it was found that the preoperatively mean abduction was $18.47 \pm 4.03$ degree which improved to $28.68 \pm 5.97$ degree at the final follow-up, which was an improvement of $10.21 \pm 5.10$ degree. According to Paired tTest this increase in abduction was highly significant $(\mathrm{p}<0.001)$. On comparing the pre-operative and final follow-up range of internal rotation movement in the patients, it was found that preoperative mean internal rotation was $11.84 \pm 5.82$ degree which increased at the final follow-up to $30.32 \pm 7.79$ degree. So a change of $18.48 \pm 6.88$ degree was seen which was highly significant $(\mathrm{p}<0.001)$ (Table I).

Table I: Comparison of preoperative \& final follow-up abduction and internal rotation.

\begin{tabular}{|c|c|c|c|c|c|}
\hline $\begin{array}{l}\text { Abduction: } \\
\text { Internal } \\
\text { rotation }\end{array}$ & $\begin{array}{l}\text { minimum } \\
\text { (in degree) } \\
\text { Abd:Ir }\end{array}$ & $\begin{array}{l}\text { maximum } \\
\text { (in degree) } \\
\text { Abd : Ir }\end{array}$ & $\begin{array}{l}\text { mean } \\
\text { (in degree) } \\
\text { Abd:Ir }\end{array}$ & $\begin{array}{l}\text { t-value } \\
\text { Abd:Ir }\end{array}$ & $\begin{array}{l}\text { p-value } \\
\text { Abd:Ir }\end{array}$ \\
\hline Preoperative & $10: 0$ & $25: 15$ & $\begin{array}{l}\text { 18.47 } \pm 4.03: \\
11.84 \pm 5.82\end{array}$ & \multirow{3}{*}{$\begin{array}{l}\text { 7.212: } \\
9.712\end{array}$} & \multirow{3}{*}{$\begin{array}{l}<0.001: \\
<0.001\end{array}$} \\
\hline $\begin{array}{l}\text { Final follow-up } \\
\text { (mean } 21.67 \pm 6.95 \text { months) }\end{array}$ & $20: 10$ & $40: 40$ & $\begin{array}{l}28.68 \pm 5.97: \\
30.32 \pm 7.79\end{array}$ & & \\
\hline Improvement (post- pre) & $10: 10$ & $15: 25$ & $\begin{array}{l}10.21 \pm 5.09: \\
18.48 \pm 6.88\end{array}$ & & \\
\hline
\end{tabular}

On comparing the preoperative and final follow-up shortening in operated limb of patients, it was found that preoperatively mean shortenings was $1.05 \pm 0.97 \mathrm{~cm}$ which was changed at final follow-up to $1.84 \pm 0.83 \mathrm{~cm}$ which was not significant $(\mathrm{p}=0.104)$. The preoperative Herring group A, group B and group C were 15.8\% (3/19), 21.1\% $(4 / 19) \& 63.2 \%$ (12/19) respectively which remain unchanged at final follow-up. So the pre and final proportion of Herring were exactly matched with $\mathrm{p}=1.000$ (Table II). 
Table II: Pre vs Post Herring lateral Pillar Status.

\begin{tabular}{|l|l|l|l|l|}
\hline \multirow{2}{*}{ Herring } & \multicolumn{2}{|l|}{ Pre-OP } & \multicolumn{2}{l|}{$\begin{array}{l}\text { at Final Follow-Up } \\
\text { (Mean 21.67 } \pm 6.95 \text { months) }\end{array}$} \\
\cline { 2 - 5 } & No. & $\%$ & No. & $\%$ \\
\hline A & 3 & 15.8 & 3 & 15.8 \\
\hline B & 4 & 21.1 & 4 & 21.1 \\
\hline C & 12 & 63.2 & 12 & 63.2 \\
\hline Total & 19 & 100.0 & 19 & 100.0 \\
\hline Significance & \multicolumn{2}{|l|}{$\mathrm{z}=000, \mathrm{p}=1.000$} \\
\hline
\end{tabular}

On comparing the preoperative and final follow-up Harris hip score, it was found that mean Harris hip score was improved from $45.47 \pm 9.28$ to $72.00 \pm 9.25$. So an improvement of $27.47 \pm 9.27$ was seen. According to student's paired t-test, this increase in Harris hip score was highly significant $(\mathrm{p}<0.001)$ (Table III).

Table III: Comparison of preoperative \& final follow-up Harris Hip Score.

\begin{tabular}{|c|c|c|c|c|c|}
\hline Harris hip score & minimum & maximum & mean \pm sd & t-value & p-value \\
\hline Preoperative & 25 & 51 & $45.47 \pm 9.28$ & \multirow{3}{*}{19.510} & \multirow{3}{*}{$<0.001$} \\
\hline $\begin{array}{l}\text { Final follow-up } \\
\text { (mean } 21.67 \pm 6.95 \text { months) }\end{array}$ & 58 & 81 & $72.00 \pm 9.25$ & & \\
\hline improvement & 33 & 30 & $27.47 \pm 9.27$ & & \\
\hline
\end{tabular}

Harris hip score was excellent in $10.5 \%(n=2)$ cases, fair in $26.3 \%(n=5)$ cases, good in $63.2 \%(\mathrm{n}=12)$ case and poor in $0 \%$ cases (Figures $1 \& 2)$.

\section{Figure 1:}

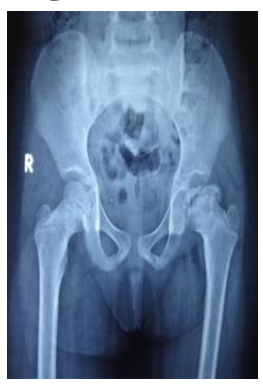

a

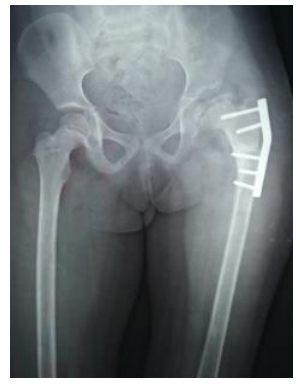

b

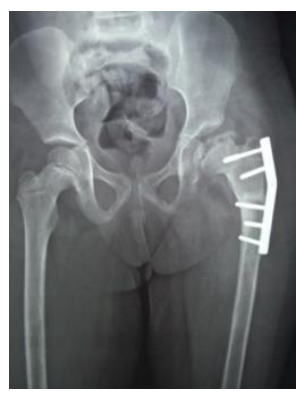

c

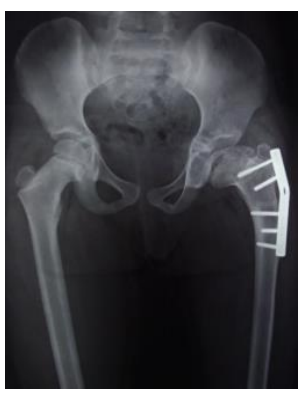

d

a: Preop. radiograph showing Perthes disease of left hip (Herring's group C). b: Immediate postop. showing proximal femoral varus derotation osteotomy and internal fixation by dynamic compression plate. C: 12 weeks follow-up showing union of osteotomy site. d: 1 year follow-up.

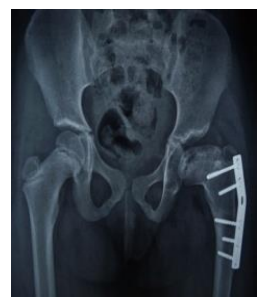

$\mathrm{e}$

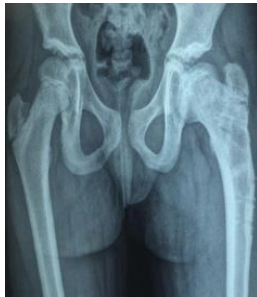

$\mathrm{f}$

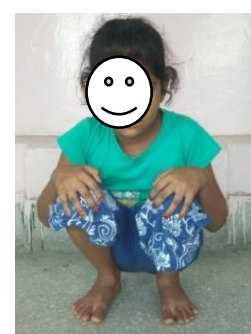

$\mathrm{g}$

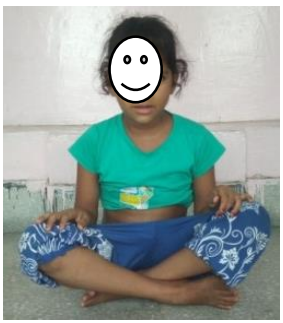

$\mathrm{h}$

e: 2 years follow-up. F: 3 years follow up after implant removal showing healed stage.

g: 3 years follow-up with squatting. H: 3 years follow-up with cross leg. 


\section{Figure 2:}

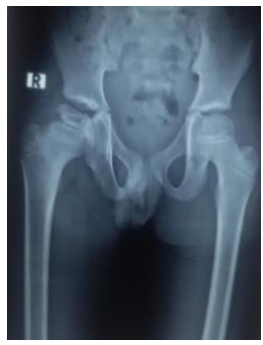

a

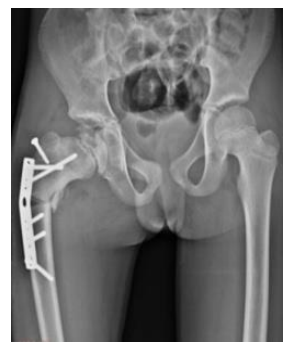

b

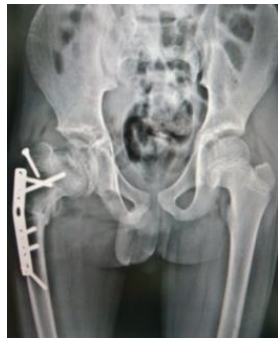

c

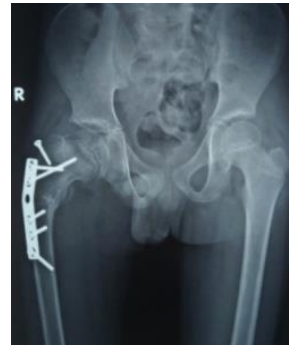

d

a: Preop. radiograph showing Perthes disease of right hip (Herring's group B). b: Immediate postop. showing proximal femoral varus derotation osteotomy and internal fixation by dynamic compression plate. C: 12 weeks follow-up showing union of osteotomy site. D: 1 year follow-up.

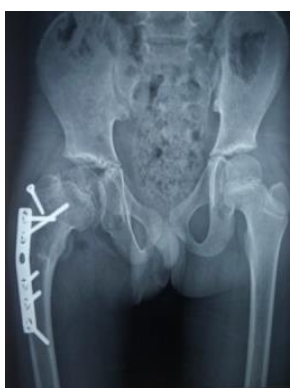

e

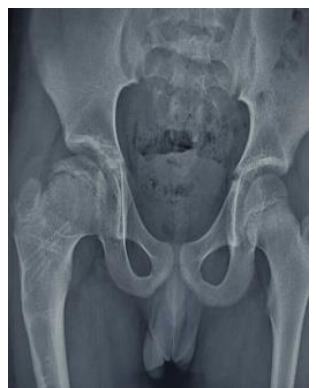

f

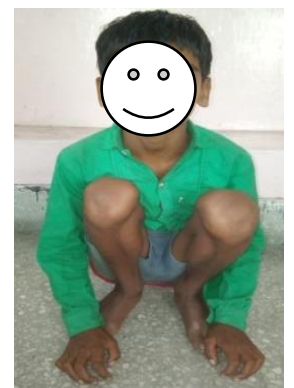

g

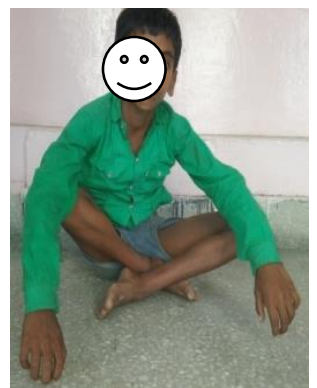

$\mathrm{h}$

e: 2 years follow-up. f: 3 years follow-up after implant removal showing healed stage. $g$ :

3 years follow-up with squatting. h: 3 years follow-up with cross leg.

\section{Discussion}

The aim of this study was to evaluate the clinico-radiological outcome of proximal femoral varus derotation osteotomy in Perthes disease in retrospectively studied patients. The decision to treat LCPD surgically is influenced by factors like; age of onset of the disease, extent of involvement of the femoral capital epiphysis, and radiographic signs ${ }^{14-18}$. Containment of the femoral head within the acetabulum is currently the preferred method of treatment which can be achieved by either non-operative or operative methods ${ }^{19}$. Initial surgical containment methods concentrated on containing the femoral head within the acetabulum by proximal femoral varus derotation osteotomy ${ }^{20,21}$.

Proximal femoral varus derotation osteotomy is a familiar procedure and it offers adequate coverage of femoral head within the acetabulum. It also decompresses the hip joint due to its femoral shortening effect. The disadvantages are limb shortening with prolonged abductor limp and possibility of persistent varus leading to trochanteric prominence. Advantage of osteotomy is that the duration of the disease can be shortened and it can bypass the stage of fragmentation to attain the regeneration phase.

Subtrochanteric osteotomy also stimulates retinacular revascularization as it augments blood flow to the femoral head and acetabulum through hypervascularization effect.

We in this study, have managed all the cases of Perthes disease with age more than 6 years by proximal femoral varus derotation osteotomy. Our study results are consistent with the findings of $\mathrm{B}$. Joseph et al in which the author had concluded that, the short-term results of early surgical containment in children over seven years of age are satisfactory. 
In our study the final functional outcome as assessed by Harris hip score was statistically significant as compared to the preoperative status ${ }^{22}$.

Raghav Saini et al in their prospective cohort study concluded that surgical intervention (proximal femoral varus derotation osteotomy) in children with severe Perthes disease, especially who are younger than 10 years of age has a good clinico-radiological outcome and is an effective and easy surgical containment method $^{23}$. They further concluded that patients with a higher degree of involvement (Herring C) tend to have greater femoral head collapse, more pronounced femoral head and neck deformities, greater restriction of the range of motion of the hip and poor prognosis ${ }^{24-26}$. We in our study also favor the surgical containment in LCPD by proximal femoral varus derotation osteotomy as we have operated on all the cases (older than 6 years of age with Herring grade A, B or C) of either gender with good functional outcome as assessed by Harris hip score.

Our study findings of good functional outcomes in Perthes disease cases managed by proximal femoral varus derotation osteotomy are consistent with the findings of C. J. Coates et al who had excellent clinical functions in all their cases managed by proximal femoral varus derotation osteotomy as assessed by Harris and Iowa scores except those cases who were managed at less than five years of age ${ }^{27}$. We had no patient in our study that got operated at less than 6 years age.
According to M. H. Moghadam et al study, proximal femoral varus derotation osteotomy is an appropriate method for treating Legg-Calve-Perthes disease patients. The outcome of this surgery was a reduction in pain, limping, and an improvement in range of motion ${ }^{28}$. We have also concluded in our study that there is a significant improvement in the range of motion, especially abduction and internal rotation.

We in our study have considered Herring classification as a radiological parameter for assessment of LCPD which shows no significant difference between preoperative and final follow-up visits in both the groups. A. Arkader et al in their study has also similar observations but on the modified Stulberg criteria ${ }^{29}$. This may be due to the reason that the follow-up was short.

In our study, we favor proximal femoral varus derotation osteotomy as preferred surgical intervention in patients of age more than 6 years of either gender as it results in better functional outcome with decreased morbidity as compared to conservatively managed cases as were evidenced in the literature.

Conclusion: According to our study, proximal femoral varus derotation osteotomy is an acceptable method for management of patients more than 6 years with Legg-Calve-Perthes disease. This surgery led to decrease in pain and Trendelenburg gait, increase in range of motion, and improvement in Harris hip score by giving a congruent hip.

\section{References}

1.Aydin BK, Sofu H, Konya MN, Er T, Sahin V. Clinical and radiographic outcomes after femoral varus derotation osteotomy for Legg-Calvé-Perthes disease at 25 years follow-up: what are the determinants of outcome in the long term?. Hip Int. 2016 May 16; 26(3): 301-6.

2.Catterall A. Legg-Calvé-Perthes' syndrome. Clin Orthop Relat Res. 1981 Jul-Aug; (158): 41-52.

3.Conway JJ. A scintigraphic classification of Legg-Calvé-Perthes disease. Semin Nucl Med. 1993 Oct; 23(4): 274-95.

4.Legg AT. An obscure affection of the hip-joint. The Boston Medical and Surgical Journal. 1910 Feb 17; 162(7): 202-4.

5.Calve J. On a particular form of pseudo-coxalgia associated with a characteristic deformity of the upper end of the femur. Clin Orthop Relat Res. 2006 Oct; 451: 14-6. 
6.Liviu Muntean. Surgical treatment in Legg Calve Perthes disease. Jurnalul Pediatrului. 2009 julydecember; Vol. XII: 47-48.

7.Herring JA, Kim HT, Browne R. Legg-Calvé-Perthes Disease: Part II Prospective Multicenter Study of the Effect of Treatment on Outcome. J Bone Joint Surg Am. 2004 Oct; 86(10): 2121-34.

8.McElwain JP, Regan BF, Dowling F, Fogarty E. Derotation varus osteotomy in Perthes disease. J Pediatr Orthop. 1985 Mar- Apr; 5(2): 195-8.

9.Grzegorzewski A, Synder M, Kozlowski P, Szymczak W, Bowen RJ. The role of the acetabulum in Perthes disease. J Pediatr Orthop. 2006 May-Jun; 26(3): 316-21.

10.Axer A. Subtrochanteric osteotomy in the treatment of Perthes' disease: A Preliminary Report. J Bone Joint Surg Br. 1965 Aug; 47: 489-99.

11.Axer A, Gershuni DH, Hendel D, Mirovski Y. Indications for femoral osteotomy in Legg-CalvéPerthes disease. Clin Orthop Relat Res. 1980 Jul-Aug; (150): 78-87.

12.Beer Y, Smorgick Y, Oron A, Mirovsky Y, Weigl D, Agar G, et al. Long-term results of proximal femoral osteotomy in Legg-Calve-Perthes disease. J Pediatr Orthop. 2008 Dec; 28(8): 819-24.

13.Joseph B, Rao N, Mulpuri K, Varghese G, Nair S. How does a femoral varus osteotomy alter the natural evolution of Perthes' disease? Journal of Pediatric Orthopaedics B. 2005 Jan 1; 14(1): 10-5.

14.Shah H. Perthes disease: Evaluation and management. OrthopClin North Am. 2014; 45: 87-97.

15.Dickens DR, Menelaus MB. The assessment of prognosis in Perthes' disease. J Bone Joint Surg Br. 1978 May; 60(2):189-94.

16.Wiig O, Terjesen T, Svenningsen S. Prognostic factors and outcome of treatment in Perthes' disease: a prospective study of 368 patients with five-year follow-up. J Bone Joint Surg Br. 2008 Oct; 90(10): 136471.

17.Mukherjee A, Fabry G. Evaluation of the prognostic indices in Legg-Calvé-Perthes disease: statistical analysis of 116 hips. J Pediatr Orthop. 1990 Mar-Apr;10(2):153-8.

18.Joseph B. Prognostic factors and outcome measures in Perthes disease. Orthop Clin North Am. 2011 Jul; 42(3): 303-15.

19.Lloyd-Roberts GC, Catterall A, Salamon PB. A controlled study of the indications for and the results of femoral osteotomy in Perthes' disease. J Bone Joint Surg Br. 1976 Feb; 58(1): 31-6.

20.Jensen OM, Lauritzen J. Legg-Calve-Perthes' disease. Morphological studies in two cases examined at necropsy. J Bone Joint Surg Br. 1976 Aug; 58(3): 332-8.

21.Salter RB. Legg-Perthes disease: the scientific basis for the methods of treatment and their indications. Clin Orthop Relat Res. 1980 Jul-Aug; (150): 8-11.

22.Joseph B, Srinivas G, Thomas R. Management of Perthes disease of late onset in southern India: the evaluation of a surgical method. J Bone Joint Surg Br. 1996 Jul; 78(4): 625-30.

23.Saini R, Goyal T, Dhillon MS, Gill SS, Sudesh P, Mootha A. Outcome of varus derotation closed wedge osteotomy in Perthes disease. Acta Orthop. Belg. 2009 Jun 1; 75(3): 334-339.

24.Ippolito E, Tudisco C, Farsetti P. The long-term prognosis of unilateral Perthes' disease. J Bone Joint Surg Br. 1987 Mar; 69(2): 243-50.

25.McAndrew MP, Weinstein SL. A long-term follow-up of Legg-Calvé-Perthes disease. J Bone Joint Surg Am. 1984 Jul; 66(6): 860-9.

26.Stulberg SD, Cooperman DR, Wallensten R. The natural history of Legg-Calvé-Perthes disease. J Bone Joint Surg Am. 1981 Sep; 63(7): 1095-1108.

27. Coates CJ, Paterson JM, Woods KR, Catterall A, Fixsen JA. Femoral osteotomy in Perthes' disease. Results at maturity. J Bone Joint Surg Br. 1990 Jul; 72(4): 581-5.

28.Moghadam MH, Moradi A, Omidi-Kashani F. Clinical outcome of femoral osteotomy in patients with Legg-Calve-Perthes disease. Arch Bone Jt Surg. 2013 Dec; 1(2): 90-93.

29.Arkader A, Sankar WN, Amorim RM. Conservative versus surgical treatment of late-onset LeggCalve-Perthes disease: a radiographic comparison at skeletal maturity. Journal of Children's Orthopaedics. 2008 Dec 11; 3(1): 21-5. 